\title{
169. Influence of crest factor on evaluation of human perception of traffic vibration
}

\author{
Alicja Kowalska-Koczwara', Krzysztof Stypuła ${ }^{2}$ \\ Cracow University of Technology, Cracow, Poland \\ ${ }^{1}$ Corresponding author \\ E-mail: ${ }^{1}$ akowalska@pk.edu.pl, ${ }^{2} k s t y p u l a @ p k . e d u . p l$
}

Received 28 November 2018; received in revised form 12 December 2018; accepted 25 December 2018 DOI https://doi.org/10.21595/jme.2018.20421

Check for updates

Copyright $(2018$ Alicja Kowalska-Koczwara, et al. This is an open access article distributed under the Creative Commons Attribution License, which permits unrestricted use, distribution, and reproduction in any medium, provided the original work is properly cited.

\begin{abstract}
In this article many vibrational signals of different value of crest factor are investigated. Evaluation of human perception of vibration is made with use of two different method of evaluation: basic RMS method and vibration dose value method (VDV), which is one of additional method mostly used for peak signals. Analysis of influence of crest factor value on evaluation of human response to vibration is made.
\end{abstract}

Keywords: vibration, human perception, crest factor, signal acceleration.

\section{Introduction}

Nowadays in more and more urbanized cities there are many sources of vibrations that could cause complaints from people residing in their houses. Some levels of vibrations can be just annoying [1,2] but the others could make staying in the room uncomfortable [3,4], which could cause insomnia, irritability, nervousness [5].

There are three methods of evaluation of human exposure to vibration according to national standards. The first one and the most popular method in standards of many countries is root mean squared method (RMS), which in ISO standard [6] is treated as a basic evaluation method.

RMS method averages acceleration values in duration time:

$a_{w}=\left[\frac{1}{T} \int_{0}^{T} a_{w}^{2}(t) d t\right]^{1 / 2}$,

where: $a_{w}(t)-$ is weighted acceleration as a function of time $\left[\mathrm{m} / \mathrm{s}^{2}\right] ; T-$ is the duration of measurement [s].

Although RMS is the basic method of evaluation in some cases additional method are required. Such situations occur when occasional shock and peaks in recorded signal appeared. In these situations so called crest factor could be very useful parameter. The crest factor is defined as the modulus of the ration of the maximum instantaneous peak value of the frequency weighted acceleration signal to its RMS value:

$C F=\frac{\left|a_{w}\right|_{P E A K}}{a_{w R M S}}$.

Different national and international standards use crest factor in different way. British standard [7] uses vibration dose value method (VDV) for evaluation of human perception of vibration. VDV is very sensitive method for peaks and occasional shocks that is why in [7] there is no need to use the crest factor parameter. In ISO standards $[6,8]$ crest factor indicate boundary between usage of RMS method and the need of usage additional methods like VDV or MTVV (maximum transient vibration value). Recorded signals with crest factor below 9 can be analysed according to RMS method, but when crest factor is higher than 9 one of additional method should be used. 
More complex information about the usage of the crest factor is included in Australian standard [9]. In this standard only two methods are considered: RMS and VDV. The usage of appropriate method results from the following algorithm:

- $\mathrm{CF}<6$ - only RMS should be used,

- $\mathrm{CF} \geq 6$ and $\mathrm{CF} \leq 9-\mathrm{RMS}$ and VDV should be used together,

- $\mathrm{CF}>9$ - only VDV should be used.

In the literature a few researchers tried to connect the value of the crest factor with the selected method of evaluation [10-14]. Mostly crest factor is considered for whole body measurements [11-13], but very interesting measurement results relating to passive perception of vibration could be find in [10]. Authors analysed different dynamical events with crest factor higher than 12 . The analysis was made using RMS, MTVV and VDV method, and the results indicate that VDV method is the best evaluation for signals with higher crest factor value. In [14] only VDV method was used for evaluation and crest factor are established to estimate the VDV. However, authors usually focused on one of the evaluation methods. This paper will analyze the two main methods currently used. Moreover, the relationship between VDV value and CF value is has been appointed and the comparative analysis was made.

In this article some examples of recorded signals with different values of crest factor are shown and two evaluation method are used (RMS and VDV). The differences in results of evaluation of human perception of vibration is analysed and discussed.

\section{Analysed building}

The building, which was chosen for analysis is located in Cracow on the Cracow University Campus. The building is five-storey rein-forced frame building with the height $23.2 \mathrm{~m}$. of It is innovative building with near zero energy consumption (see Fig. 1).

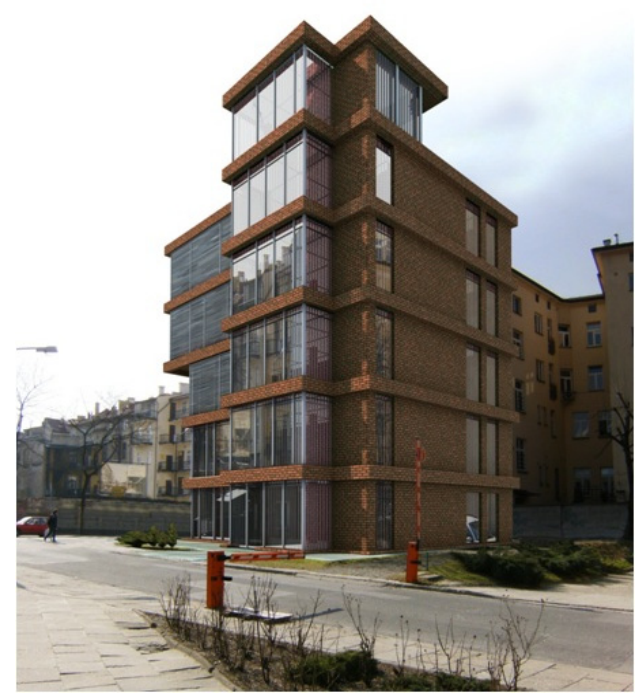

Fig. 1. View of the building

Parameters like thermal comfort, humidity, lightness etc. are monitored 24 hours a day. No one, however, thought about vibrational comfort in this building located very close to road (about $1.5 \mathrm{~m}$ ). People who work in this building started complain for vibrations. That is why on summer of 2017 measurements of human response to vibration were made. Measurement sensors were located on the second and the fifth floor. In both locations perception threshold of vibration was exceeded, moreover in some cases comfort level was also exceeded. For this reason more complex signal analysis was made using two methods of evaluation. 


\section{Measurement methodology}

24 hour monitoring was done, and 1000 dynamical events, in which external source was identified to be traffic excitation were recorded. The sources of vibration excitation were: modal tests with a modal hammer; traffic on a nearby street, controlled passage through the threshold of light truck release, synchronized movement of men at the top level of the building. Measurement points for both locations (on the second and on the fifth floor) were placed in the middle of the floor acc. [15]. The instrumental system consisted of PCB 393B12 accelerometers, a digital analyser LMS Mobile Scadas equipped with an analogue low-pass Butterworth filter 0-100 Hz. Piezoelectric accelerometers were installed to measure horizontal components of vibrations in two mutually perpendicular directions $x$ and $y$ and vertical direction $z$ (see Fig. 3). An example of waveform obtained during measurements is shown in Fig. 2.

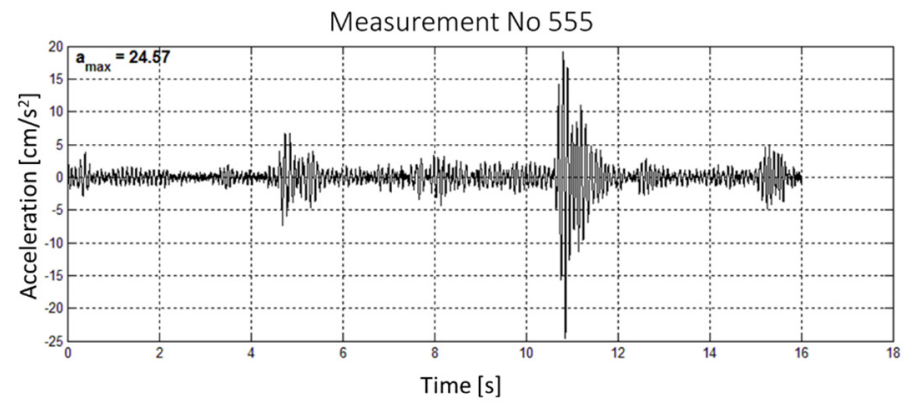

Fig. 2. Waveform recorded on the fifth floor in $z$ direction

Waveforms obtained from monitoring were used for both RMS and VDV analysis according to appropriate algorithm available in [15].

\section{Results of RMS method}

For almost 30 signals recorded on the second floor human perception threshold was exceeded. Exceedance of comfort level on this floor occurred during the night, but this building is an office building, in which people do not stay in the nighttime.

Much worse situations occurred in the conference room, which is located on the fifth floor (see Fig. 3).



Fig. 3. Conference room with measurement disc located in the center area of the room

In this room comfort level was exceeded in about 50 of 1000 recorded signals and exceedance occurred during daytime. An example of RMS analysis in the one third octave bands is shown in Fig. 4. 


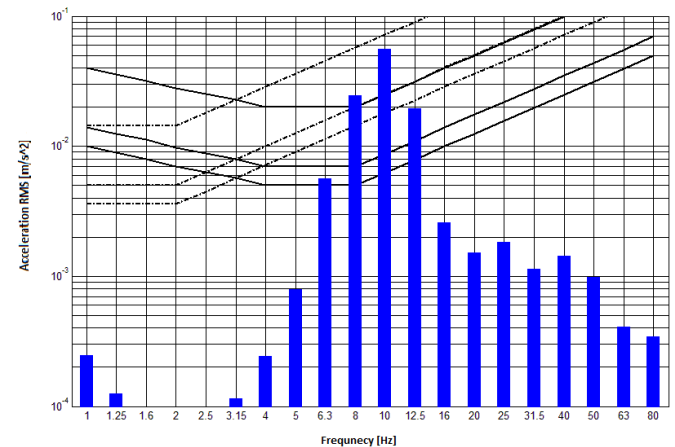

Fig. 4. RMS analysis of the measurement in the conference room

\section{Results of VDV method}

Analysis according to VDV method was made based on VDV procedure enclose in Polish standard [15]:

$V D V=\left[\int_{0}^{T} a_{w}^{4}(t) d t\right]^{\frac{1}{4}}$

Evaluation of human perception of vibration according to VDV method was made using comfort levels, which relate to probability of adverse comments. Probability of complains is listed in Table 1 (according to [15]).

Table 1. Levels of probability of adverse comments

\begin{tabular}{|c|c|c|c|}
\hline Type of the room & Time of day & $\begin{array}{c}\text { Low probability } \\
\text { of adverse comments }\end{array}$ & $\begin{array}{c}\text { Adverse comments } \\
\text { possible }\end{array}$ \\
\hline- & - & {$\left[\mathrm{m} / \mathrm{s}^{1.75}\right]$} & {$\left[\mathrm{m} / \mathrm{s}^{1.75}\right]$} \\
\hline $\begin{array}{c}\text { Hospitals, operating theatres, } \\
\text { precise laboratories }\end{array}$ & Day and night & 0.10 & 0.20 \\
\hline Residential & Day & 0.20 & 0.40 \\
\hline Office & Night & 0.13 & 0.26 \\
\hline Workshops & Day and night & 0.40 & 0.80 \\
\hline & Day and night & 0.80 & 1.60 \\
\hline
\end{tabular}

On the second floor in about 36 recorded signals VDV value is in the middle range of adverse comments from 0.4 to 0.8 and in 8 signals VDV value exceeds 0.8 , which could be interpreted as exceedance of comfort level. As in RMS method much worse situation occurred on the fifth floor in almost 60 recorded signals value of 0.8 is exceeded. What is worth noting that this exceedance does not always occurs in signals, in which according to RMS method comfort level is exceeded.

\section{Comparative analysis of two method of evaluation}

In the Table 2 analysis of 20 dynamical events of different values of crest factor ( 5 events have crest factor value below 6 , another 5 have crest factor higher than 9 and 10 dynamical signals with crest factor from between 6 and 9) is shown. These twenty recorded signals were chosen because of differences in result of evaluations based on RMS and VDV analysis.

To compare VDV value with RMS method, which mostly is illustrated on the graph WODL factor is needed [15]: 
$W O D L=\max \left(\frac{a_{R M S}}{a_{z}}\right)$,

where: $a_{R M S}$ - acceleration RMS value obtained from analysis; $a_{z}$ - acceleration RMS value equivalent to the threshold for the perception of vibration in a $z$ direction in the same $1 / 3$ octave band as in $a_{R M S}$.

Table 2. Comparative analysis of two evaluation method with respect to the value of crest factor

\begin{tabular}{|c|c|c|c|}
\hline \multirow{2}{*}{ No. } & Crest factor value & WODL value & VDV value \\
\hline & {$[-]$} & {$\left[\mathrm{m} / \mathrm{s}^{2}\right]$} & {$\left[\mathrm{m} / \mathrm{s}^{1.75}\right]$} \\
\hline 1 & \multirow{5}{*}{$0.00-5.99$} & 4.03 & 0.50 \\
\hline 2 & & 4.32 & 0.46 \\
\hline 3 & & 5.19 & 0.57 \\
\hline 4 & & 2.26 & 0.38 \\
\hline 5 & & 1.61 & 0.32 \\
\hline 6 & \multirow{10}{*}{$6.00-9.00$} & 5.76 & 0.58 \\
\hline 7 & & 2.11 & 0.32 \\
\hline 8 & & 1.87 & 0.29 \\
\hline 9 & & 1.27 & 0.25 \\
\hline 10 & & 1.11 & 0.27 \\
\hline 11 & & 1.13 & 0.27 \\
\hline 12 & & 0.99 & 0.41 \\
\hline 13 & & 0.81 & 0.59 \\
\hline 14 & & 1.18 & 0.38 \\
\hline 15 & & 1.45 & 0.37 \\
\hline 16 & \multirow{5}{*}{$>9.00$} & 4.91 & 0.58 \\
\hline 17 & & 1.49 & 1.41 \\
\hline 18 & & 0.42 & 0.41 \\
\hline 19 & & 1.24 & 1.22 \\
\hline 20 & & 5.22 & 0.79 \\
\hline
\end{tabular}

The summary and the novelty of the considerations regarding the influence of the crest factor on the values of the WODL factor and the value of the VDV vibration dose is the observation that the vibration dose correlates better with the crest factor values than the WODL factor. Although this relationship is not strong, the coefficient of determination is $R^{2}=0.624$, then a marked increase in the VDV value is visible with the increase of the crest factor (Fig. 5).

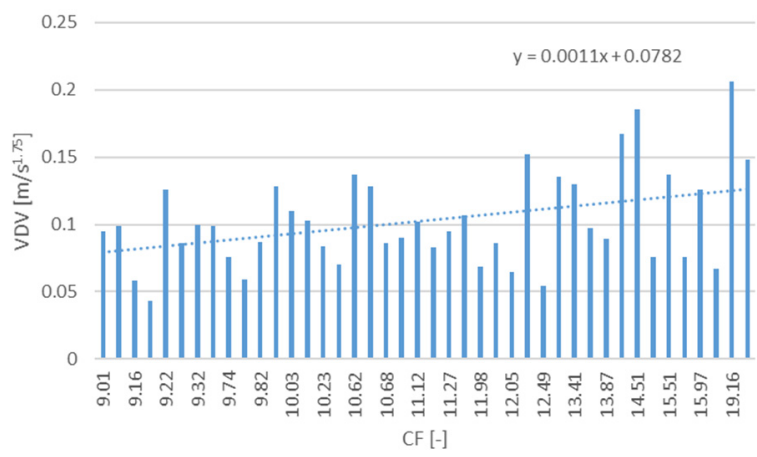

Fig. 5. The influence of CF values on VDV analysis

\section{Conclusions}

About 1000 recorded signals were investigated and evaluation of human perception of 
vibrations was made using both RMS and VDV method. Mostly result of evaluation is the same for these methods, but there are cases, in which they differ from each other. For the purpose of this article analysis of 20 recorded signals, which differ a lot, was shown.

Despite of value of the crest factor differences in results of evaluation based on two methods occurred. Much more restrictive with higher level of safety in most cases is evaluation made by using the RMS value obtained according to standard regulations of [15]. It is because of algorithm of determination of RMS value. First of all, in [15] duration of vibration last when amplitudes are higher than 0.2 of maximum amplitude. In classical RMS method registration should last min. 30 minutes. Than evaluation is made according to maximum dynamical event, which occur during measurement. That is why this method is closer to MTVV method, which is one of additional method in ISO standard [6].

During analysis it succeed to determine the relationship between crest factor value and vibration dose value in the range of $\mathrm{CF}>9$. This relationship could be very useful in preliminary prediction of VDV value and hence prediction if dynamical comfort is exceeded.

The differences in measurement results for the second and the fifth floor were significant. On the second floor there was no dynamical event, in which comfort level was exceeded. On the highest fifth floor there were several events, in which comfort level was exceeded.

\section{References}

[1] Hunaidi O., Trembaly M. Traffic induced building vibrations in Montreal Canadian Journal of Civil Engineering, Vol. 24, Issue 5, 1997, p. 736-753.

[2] Haoa H., Anga T. C., Shen J. Building vibration to traffic-induced ground motion. Building and Environment, Vol. 36, 2001, p. 321-336.

[3] Watts G. R., Krylov V. V. Ground-borne vibration generated by vehicles crossing road humps and speed control cushions. Applied Acoustics, Vol. 59, 2000, p. 221-236.

[4] Pavic A., Reynolds P. Vibration Serviceability of Long-Span Concrete Building Floors: Part 1 Review of Background Information. University of Sheffield, Department of Civil and Structural Engineering, 2002, p. 1-81.

[5] Smith M. G., Croy I., Ögren M, Persson Waye K. On the influence of freight trains on humans: a laboratory investigation of the impact of nocturnal low frequency vibration and noise on sleep and heart rate. PlosMedicine, Vol. 8, Issue 2, 2013, p. 1-9.

[6] Mechanical Vibration and Shock: Evaluation of Human Exposure to Whole-Body Vibration - Part 1: General Requirements. International Organization for Standardization, ISO 2631-1, 1997.

[7] Guide to Evaluation of Human Exposure to Vibration in Buildings. Vibration Sources other than Blasting. British Standards Institution, BS 6472-1, 2008.

[8] Mechanical Vibration and Shock - Evaluation of Human Exposure to Whole-Body Vibration - Part 2: Vibration in Buildings (1 Hz to $80 \mathrm{~Hz}$ ). International Organization for Standardization, ISO 2631-2, 2003 .

[9] Evaluation of Human Exposure to Whole-Body Vibration Continuous and Shock-Induced Vibration in Buildings (1 to $80 \mathrm{~Hz}$ ). AS 2670.2, 1990.

[10] Caprioli A., Reynolds P., Vanali M. Evaluation of serviceability assessment measures for different stadia structures and different live concert events. IMAC XXV, Orlando, Florida, 2007.

[11] Johanning E., Fischer S., Christ E., Göres B., Landsbergis P. Whole-body vibration exposure study in U.S. Railroad Locomotives - an ergonomic risk assessment. AIHA Journal, Vol. 63, Issue 4, 2002, p. 439-446.

[12] Johanning E. Vibration and shock exposure of maintenance-of-way vehicles in the railroad industry. Applied Ergonomics, Vol. 42, Issue 4, 2011, p. 555-562.

[13] Lines J., Stiles M., Whyte R. Whole body vibration during tractor driving. Journal of Low Frequency Noise, Vibration and Active Control, Vol. 14, Issue 2, 1995, p. 87-104.

[14] Setareh M. Vibration serviceability of a building floor structure. II: vibration evaluation and assessment. Journal of Performance of Constructed Facilities, Vol. 24, Issue 6, 2010.

[15] Evaluation of Vibrations Influence on People in Buildings. Polish Standard, PN-B-02171:2017-06, 2017, (in Polish). 